NACIONAL

\title{
Violencia sexual y de género y los mecanismos de protección jurídica en la legislación laboral chilena
}

\author{
Sexual and gender violence and legal mechanisms of protection in Chilean labor law
}

\section{Sergio Esteban Mundaca Castillo}

\author{
Universidad de Chile
}

\begin{abstract}
RESUMEN El presente artículo es una revisión de la legislación laboral chilena en búsqueda de las respuestas legislativas que se otorgan a las situaciones de violencia sexual y de género sufridas por las personas en el contexto de la empresa. Para ello, se analizan en primer momento los conceptos de violencia sexual y de género, con un repaso de aquello que implica cada uno de los mismos. Posteriormente, se analizan los mecanismos que la legislación nacional laboral otorga para hacer frente a tales vulneraciones, para dar cuenta de que los mismos tienen una dimensión represiva y no disuasiva. Así las cosas, se revisa la aplicación de las obligaciones de contenido del reglamento interno de orden, higiene y seguridad; el despido por causal grave; el despido indirecto; el procedimiento de tutela laboral, y la denuncia ante la inspección del trabajo. Finalmente, se revisa su utilidad para evitar la ocurrencia de situaciones de violencia sexual o de género, de sancionarlas y, en definitiva, el resguardo de los derechos de la persona que sufra tales vulneraciones.
\end{abstract}

PALABRAS CLAVE Violencia sexual, violencia de género, protección del trabajador, acoso laboral, igual remuneración.

ABSTRACT The following article is a review of Chilean labor law that searches for legal answers to sexual and gender violence suffered by people in the workplace context. Firstly, the concepts of sexual and gender violence are analyzed. Then, the mechanisms that the national labor law gives to deal with the violations are analyzed, exposing that they have a repressive rather than a dissuasive dimension. With that in mind, the mandatory contents of the Order, Hygiene and Safety Internal Regulation, dismissal by severe grounds, indirect dismissal, the labor protection procedure and the complaints before the Labor Inspection are reviewed. Finally, the effectiveness of those mechanisms in preventing the occurrence of sexual or gender violence, in sanctioning them and in protecting the rights of the person who suffered such violations will be reviewed. 
KEYWORDS Sexual violence, gender violence, worker protection, workplace harassment, equal remuneration.

\section{Introducción}

El análisis que se presenta tiene como finalidad otorgar una visión respecto de las herramientas que se otorgan para enfrentar situaciones de violencia sexual y de género en el Código del Trabajo, por lo que se interioriza en la situación actual de las instituciones relacionadas que allí se recogen y la forma en que los medios que se otorgan al afectado por situaciones de vulneración pueden utilizarse, además de su funcionamiento. Finalmente, se busca analizar si tales mecanismos de defensa resultan suficientes para dar cara a las situaciones vejatorias que puedan ser vividas en este contexto.

Resulta trascendental plantearse estas interrogantes, puesto que, como señala la Organización Mundial de Salud:

Los estudios iniciales indican que el problema está muy difundido, especialmente porque más mujeres se incorporan a la fuerza laboral. Las encuestas han revelado que $40 \%$ a $50 \%$ de las mujeres de la Unión Europea han sufrido alguna forma de acoso sexual o comportamiento sexual no deseado en el lugar de trabajo (Comisión Europea, 1998: iii).

En el estudio más reciente al respecto, publicado en 2014 por la Agencia de la Unión Europea para los Derechos Humanos, se señala que esta cifra ha disminuido a $20 \%$ de las mujeres (Agencia Europea de Derechos Fundamentales, 2014). A su vez, en la realidad nacional, según antecedentes del Instituto Nacional de Estadísticas (INE), en 2016 el 38,1\% de los trabajadores asalariados eran mujeres, lo que equivale a cerca de 3.500.00o personas. De ellas, el 57,3\% lo hacía en virtud de un contrato de trabajo, fuera a plazo fijo $(24,5 \%)$ o con contrato indefinido ( $32,8 \%)$. A su vez, el $28,8 \%$ se encontraban prestando servicios en jornada parcial (30 o menos horas a la semana), cerca del 19,6\% en jornada intermedia ( 31 a 44 horas semanales) y 51,6\% en jornada completa (45 o más horas a la semana) (Instituto Nacional de Estadísticas, 2016).

De esta forma, en 2016, aproximadamente 1.707.325 mujeres estuvieron en una empresa, sometidas a subordinación y dependencia, durante 45 o más horas a la semana, vale decir, a lo menos entre 7,5 y 9 horas diarias dentro del recinto en que prestan servicios. Lo que hace que resulte de relevancia dar una visión a las posibles formas de vulneración que pueden sufrir y las respuestas que la legislación laboral les otorga ante ellas.

Para ello, se presentan tres grandes partes: una introductoria en la que se presentan conceptos claves para la dilucidación de nuestros fines; se pasa luego a una parte central, en la que se revisan los mecanismos que el Código del Trabajo ofrece a la 
persona vulnerada en sus derechos para hacer frente a las mismas, relacionándolas y explicando su funcionamiento ante cada tipo de afección, para finalmente indicar si resultan idóneas para la finalidad buscada.

\section{Conceptos clave}

Con el objetivo de dotar al lector de herramientas clave para entender el análisis propuesto en este trabajo, el presente apartado otorga ciertos conceptos fundamentales en la materia.

Como un preámbulo de las definiciones que pretendemos otorgar, señalaremos que, en vista de que no resulta fácil separar la violencia sexual de la violencia de género, es trascendental plantear el concepto de sexualidad y lo que la compone, para así buscar elementos que permitan diferenciarlas. Este término es un constructo en que tiene especial importancia el proceso de socialización, referido a las maneras en que la sociedad transmite al individuo sus normas o expectativas en cuanto a su comportamiento (Shibley Hide y DeLamater, 2006: 339-341). En otras palabras, «la socialización consiste en el proceso de internalización de valores, creencias y formas de percibir el mundo, que son compartidas por un grupo» (Gauché Marchetti, 2011: 72).

Dicho lo anterior, debe entenderse que la sexualidad, como concepto complejo, involucra mucho más que el sexo de un ser humano, pues incluye, entre otros, el género de una persona y su orientación sexual. Estos aspectos toman distintas formas y se expresan de diversos modos en cada ser humano, sea mediante gestos, palabras, sentimientos, valores, fantasías o creencias, que se construyen a lo largo de la vida y condicionan las relaciones con los demás, puesto que forman una esencial faceta de la identidad personal, en particular, la identidad sexual (Gauché Marchetti, 2011: 72).

En este sentido, ha de precisarse, brevemente, el concepto de cada uno de los elementos más importantes que conforman la sexualidad, para así dotar de contenido a esta poderosa palabra.

El sexo, como elemento biológico de la sexualidad, se refiere a las diferencias biológicas entre hombres y mujeres, que se proyectan en la anatomía, fisiología y respuestas sexuales del individuo. Sus componentes son: i) la composición cromosómica; ii) los órganos reproductores; iii) los genitales externos; iv) los genitales internos; v) el componente hormonal, y vi) las características sexuales secundarias'. De esta forma, el sexo será la caracterización biológica, en principio, ajena a la voluntad de la persona.

En segundo término, la dimensión constructiva social, es decir, el género de la persona, se define según su función, consistente en poner de relieve un sistema com-

1. Todos estos elementos superan las finalidades de este ensayo, por lo cual no son explicadas. Sin embargo, para un análisis profundo y detallado al respecto, véase Gauché Marchetti (2011: 74-78). 
pleto de relaciones, que, si bien puede incluir el sexo, no está directamente determinada por el mismo. Por el contrario, este elemento es, en primer lugar, constitutivo de las relaciones sociales basadas en las diferencias que distinguen los sexos y, en segundo término, la forma primaria de relaciones significativas de poder. Hemos de señalar en breve que: «Género es hoy una construcción social compleja, [...] habla del lenguaje de masculinidad y feminidad, en código de lo que significa ser varón o ser mujer en una sociedad determinada» (Gauché Marchetti, 2011: 81).

Como último elemento, de los más relevantes a la hora de determinar la sexualidad, está la conducta sexual del individuo, vale decir, su orientación sexual, caracterizada como la «tendencia interna y estable que provoca tener reacciones psicológicas de tipo sexual, así como el deseo de mantener conductas sexuales con personas del mismo, o diferente, sexo» (Baile Ayensa, 2008: 30).

Dicho lo anterior, debemos revisar el concepto general de violencia, en el cual se denotan elementos clave. En primer lugar, se la define como el uso efectivo o la amenaza de usar intencionalmente la fuerza física o el poder, en contraposición a uno meramente accidental. Vale decir, cuando conscientemente se desea emplear la violencia, y no cuando, sabiéndose que puede influirse en un actuar ajeno en virtud de una posición de privilegio o especial, se actúa de igual forma aceptando que el posible resultado pueda ser vulneratorio de derechos. En segundo lugar, se señala que la acción debe tener posibilidades de o efectivamente causar lesiones, muerte, daño psicológico, trastornos del desarrollo o privaciones, lo que considera, por tanto, un efecto en la vida, integridad física o psíquica de aquel que la recibe. Así, se dejan fuera posibles lesiones o daños en aspectos fundamentales pero no amparados dentro de la vida o integridad física o, incluso, psíquica, sino que, por ejemplo, dentro de la esfera económica del individuo, como podría ser la pérdida del trabajo o limitar el posible crecimiento de una persona dentro de una empresa (Oficina Regional para las Américas de la Organización Mundial de la Salud, 2002).

En particular, son elementos clave de la violencia sexual, primero, cualquier acto sexual, incluso comentarios o insinuaciones de tal carácter. En segundo lugar, que, con frecuencia, la relación entre agresor y víctima se funda en una asimetría de poder y la coerción que ejerce el primero es una forma de dominación sobre el segundo, sin que importe la relación que entre los sujetos pueda existir. Tercero, que puede darse en cualquier contexto o ámbito. Por último, debe resaltarse que la notoriedad de las lesiones físicas que se producen en las víctimas de violencia sexual no se relaciona necesariamente con la magnitud del impacto sobre la misma, pues generalmente las secuelas psicológicas son las que muestran consecuencias más claras en distintos aspectos de la vida de la víctima a corto, mediano y largo plazo (Servicio Médico Legal, 2016; Jewkes, 2002: 1.423-1.429)².

2. En igual sentido indica la Organización Mundial de la Salud en su comunicado de noviembre de 
Por tanto, para la finalidad de este trabajo, entenderemos por violencia sexual la coacción, física o moral, que se produce en contra de una persona, mayoritariamente mujeres ${ }^{3}$, que involucre o tienda a involucrar un acto de características sexuales, ejercido en la esfera pública o privada del o los individuos afectados.

En cuanto a la violencia de género, en la ley gallega, para prevenir y sancionar la violencia de género, se señala que lo es:

Cualquier acto violento o agresión, basados en una situación de desigualdad en el marco de un sistema de relaciones de dominación de los hombres sobre las mujeres que tenga o pueda tener como consecuencia un daño físico, sexual o psicológico, incluidas las amenazas de tales actos y la coacción o privación arbitraria de la libertad, tanto si ocurren en el ámbito público como en la vida familiar o personal (Ley 11/2007 Para la Prevención y el Tratamiento Integral de la Violencia de Género, Presidencia de la Junta de Galicia, 27 de julio de 2007).

Por su parte, Naciones Unidas considera que importa:

Todo acto de violencia de género que resulte, o pueda tener como resultado un daño físico, sexual o psicológico para la mujer, inclusive la amenaza de tales actos, la coacción o la privación arbitraria de libertad, tanto si se produce en la vida pública como la privada ${ }^{4}$.

Por tanto, entenderemos por violencia de género, la coacción, física o moral, que se produce en contra de una persona o grupo de personas en atención al rol que habitualmente su entorno cultural le asigna a la construcción social a la que adscribe, mayoritariamente la femenina ${ }^{5}$, con la finalidad de mantener el control sobre la víctima, para obligarla a actuar según los parámetros presentes en el agresor, lo que tiene como resultado, o posible resultado, un daño físico, sexual o psicológico, sea éste presente o futuro, ejercido en la esfera pública o privada del o los individuos afectados.

Habiendo dejado claro tales conceptos, habrá de revisarse cuáles son las respuestas que otorga nuestro ordenamiento jurídico en materia de derecho del trabajo, para enfrentarlos y determinar su suficiencia.

2016 publicado por su Centro de Prensa, disponible en http://bit.ly/VNwSyz.

3. Al respecto, según cifras publicadas por la Dirección del Trabajo, el 2008, de un total de 302 denuncias recibidas, el 96,8\% corresponde a mujeres (Carrasco Oñate y Vega López, 2009).

4. Citado en el comunicado de la Organización Mundial de la Salud de noviembre de 2016.

5. Se reconoce que la violencia de género no es la que se ejerce en contra de una mujer sólo por el hecho de serlo en Corcoy Bidasolo (2010: 305-347). 


\section{Mecanismos de protección jurídica en la legislación laboral chilena}

En el presente apartado se analizan los mecanismos de protección jurídica que otorga la legislación laboral, sin perjuicio de que, como se verá, ellos no resultan serlo, sino que normalmente nos encontramos con que el Código del Trabajo otorga, más bien, mecanismos represivos ante una vulneración de carácter sexual y de género, en lugar de buscar resguardar que ellos no ocurran.

Ahora bien, resulta indicado precisar que

la protección del trabajador se materializa por una doble vía. Por un lado, se mantiene la tutela tradicional contenida en el ordenamiento jurídico laboral, manifestada en el ámbito de las relaciones contractuales individuales, en el otorgamiento de un conjunto de derechos mínimos irrenunciables a favor del trabajador que limitan la autonomía de la voluntad de las partes del contrato de trabajo y, en el ámbito de las relaciones colectivas, mediante el reconocimiento de la autotutela colectiva expresada en el ejercicio de la libertad sindical. Por otro lado, la aceptación de la ciudadanía laboral agrega todo el abanico de protección a la esfera individual de las personas que conllevan los derechos fundamentales consagrados tanto en la Constitución, como en los instrumentos internacionales sobre derechos humanos ratificados por Chile, los que se van a erigir como un límite natural al ejercicio de los poderes empresariales, como a su vez, en valores orientadores e integradores de la normativa laboral tradicional (Caamaño Rojo, 2001: 216-217).

Es este segundo punto el que la doctrina laboral llama «ciudadanía en la empresa» o «derechos laborales inespecíficos» (Gamonal Contreras, 2004; Ugarte, 2009a).

De esta forma, excluiremos en esta oportunidad el análisis de la aplicación horizontal de los derechos fundamentales no propiamente laborales como límite de los poderes del empleador (Gamonal Contreras, 2008), para centrarnos únicamente en aquellos mecanismos que el Código del Trabajo reconoce expresamente ${ }^{6}$.

Así las cosas, se divide este apartado en: 1) obligaciones de contenido del reglamento interno de orden, higiene y seguridad; 2) despido indirecto o autodespido; 3 ) procedimiento de tutela laboral, y 4) denuncia ante la Inspección del Trabajo.

Obligaciones de contenido del reglamento interno de orden, higiene y seguridad

Se define este reglamento como el conjunto normativo, emanado del empresario, que regula el funcionamiento interno de la empresa en sus diversos aspectos (Thayer y Novoa Fuenzalida, 2009: 159).

Se encuentran obligadas a tener un reglamento, de acuerdo con el artículo 153

6. Sin perjuicio de ello, un texto de consulta obligada al respecto es Gamonal Contreras (2015). 
del Código del Trabajo, todas aquellas empresas, establecimientos, faenas o unidades económicas que ocupen normalmente diez o más trabajadores permanentes. A su vez, ha de destacarse aquello señalado por el artículo 156 del Código del Trabajo, en el sentido de que debe ponerse en conocimiento de los trabajadores treinta días antes de que empiece a regir, fijarse a lo menos en dos sitios visibles del lugar de las faenas y, por último, que el empleador deberá entregar gratuitamente a los trabajadores un ejemplar, con lo que la ley busca cerciorarse de que el trabajador pueda conocer los preceptos que allí se contienen antes de verse obligado a cumplirlos.

Esto cobra especial relevancia, toda vez que no es la autoridad administrativa la que debe de revisar y aprobar el reglamento presentado por el empleador -sin perjuicio de que puede revisarlo y ordenar modificaciones de oficio-, sino que la ley deja tal función, eminentemente, a los propios afectados por el mismo, al señalar en el artículo 153 del Código del Trabajo, inciso final, que el delegado del personal, cualquier trabajador o las organizaciones sindicales de la empresa podrán impugnar las disposiciones que estimaren ilegales, exigir su modificación o solicitar que se incorpore alguna de las menciones obligatorias del mismo.

Si bien, como se dijo, el reglamento emana únicamente de la voluntad del empresario, con la finalidad de normar el funcionamiento de la empresa, la legislación establece determinados contenidos que, a lo menos genéricamente, han de aparecer en el mismo. Todo lo cual se encuentra en el artículo 154 del Código del Trabajo, siendo relevantes, para nuestros fines, los numerales siguientes:

12. El procedimiento al que se someterán y las medidas de resguardo y sanciones que se aplicarán en caso de denuncias por acoso sexual.

En el caso de las denuncias sobre acoso sexual, el empleador que, ante una denuncia del trabajador afectado, cumpla íntegramente con el procedimiento establecido en el título 4 del libro 2, no estará afecto al aumento señalado en la letra c) del inciso primero del artículo 168, y

13. El procedimiento a que se someterán los reclamos que se deduzcan por infracción al artículo 62 bis. En todo caso, el reclamo y la respuesta del empleador deberán constar por escrito y estar debidamente fundados. La respuesta del empleador deberá ser entregada dentro de un plazo no mayor a treinta días de efectuado el reclamo por parte del trabajador (Decreto con Fuerza de Ley 1 que Fija el Texto Refundido, Coordinado y Sistematizado del Código del Trabajo, artículo 2).

Resulta, por tanto, que como contenido mínimo del reglamento debe haber una respuesta jurídica ante posibles situaciones de violencia sexual que puedan existir dentro del contexto de la empresa, lo que obliga al empleador a establecer un procedimiento al cual someter denuncias por acoso sexual. A su vez, como respuesta jurídica ante violencia de género, se le obliga a otorgar un procedimiento escrito para recibir y dar respuesta de diferencias en los salarios, para el mismo cargo, entre 
hombres y mujeres (artículo 61 bis del Código del Trabajo). Revisaremos, por tanto, ambas obligaciones.

\section{Respecto de la denuncia por acoso sexual}

Consideraciones previas. Dicho lo anterior, puede verse el concepto que otorga el Código del Trabajo al tratar esta situación de violencia sexual, en su artículo 2, inciso 2, que indica:

Las relaciones laborales deberán siempre fundarse en un trato compatible con la dignidad de la persona. Es contrario a ella, entre otras conductas, el acoso sexual, entendiéndose por tal el que una persona realice en forma indebida, por cualquier medio, requerimientos de carácter sexual, no consentidos por quien los recibe y que amenacen o perjudiquen su situación laboral o sus oportunidades en el empleo.

Es relevante destacar que se recoge este tipo con limitaciones que pueden interpretarse con absoluta discrecionalidad. En este sentido, el Código pareciera asumir que existen requerimientos de carácter sexual realizados de forma debida, pese a no ser consentidos por quien los recibe. De igual forma, en cuanto a que la antijuricidad se da si los requerimientos no son consentidos por quien los recibe, pareciera limitarse la posibilidad de denuncia únicamente a la víctima, en tanto será sólo ella la que podrá determinar si los requerimientos indicados son o no consentidos (Carrasco Oñate y Vega López, 2009: 37). Y, por último, se relaciona esta conducta con un efecto reducido y limitado, como amenazar o perjudicar su situación laboral u oportunidades en el empleo, lo que deja fuera cualquier conducta con requerimientos sexuales, no consentida, indebida y ejercida por cualquier medio en contra de la víctima que no amenace o perjudique su situación laboral u oportunidades en el empleo ${ }^{8}$.

Se aparta la legislación laboral chilena de la definición que la Organización Internacional del Trabajo recoge como acoso sexual, puesto que ella señala:

Insinuaciones sexuales indeseables, o un comportamiento verbal o físico de índole sexual que persigue la finalidad o surte el efecto de interferir sin razón alguna en el rendimiento laboral de la persona, o bien de crear un ambiente de trabajo intimidante, hostil, injurioso u ofensivo (Organización Internacional del Trabajo, 2003: 14).

No se limita allí a que las insinuaciones o comportamientos se realicen de forma indebida; a su vez, no restringe la antijuridicidad de la conducta a que la víctima consienta en recibir los requerimientos, pues señala que las prácticas o insinuaciones deberán ser indeseables, lo que podría también ser calificado por terceros ajenos a la

7. Para un muy buen análisis sobre esta institución, véase Carrasco Oñate y Vega López (2009).

8. Estas críticas son plasmadas en mayor detalle en Ramos Muñoz y Sánchez Romero (2015). 
vulneración. Por último, se acepta que el efecto de la conducta no es sólo el señalado por la legislación nacional, sino que también puede ser el de afectar el rendimiento laboral de la persona, o el de crear un ambiente de trabajo intimidante, hostil, injurioso u ofensivo, lo que amplía el reconocimiento que realiza la legislación nacional.

Del procedimiento de denuncia. Ahora bien, en cuanto al contenido obligatorio del reglamento, se señala que debe incluir el procedimiento y las medidas de resguardo y sanciones que se aplicarán en caso de acoso sexual, al indicar que, si la investigación se ciñe al procedimiento establecido por la ley, no procederá el aumento de $80 \%$ de la indemnización que corresponde al trabajador encontrado culpable, por lo cual resulta desvinculado, cuando, en definitiva, el mismo es encontrado inocente en un procedimiento posterior seguido ante los tribunales laborales.

El procedimiento señalado se regula en los artículos 211-A, 211-B, 211-C, 211-D y 211-E del Código del Trabajo. Allí se indica, en primer lugar, que la persona afectada deberá hacer llegar su reclamo por escrito a la dirección de la empresa, establecimiento o servicio o a la respectiva Inspección del Trabajo. Se ha entendido que, cuando es el propio empleador el denunciado por acoso sexual, debe recurrirse directamente a la Inspección del Trabajo, aun si el reglamento contuviera un procedimiento interno ante acoso sexual (Ordinario 1133/36 de la Dirección del Trabajo).

De esta forma, se iniciará el procedimiento sólo con el reclamo escrito presentado por la víctima, que ha de contener su individualización, una descripción de los hechos denunciados y la referencia a quien fuera responsable. Con ello, no se permite a trabajadores que conocen de la ocurrencia de situaciones de acoso sexual en contra de alguno de sus colegas denunciar por ellos. Sin embargo, según ha dispuesto la Dirección del Trabajo, sí puede denunciar, en lugar de la víctima, el sindicato al cual se encuentre afiliada (Ordinario 1133/36 de la Dirección del Trabajo).

A su vez, no se determina un área en específico de la dirección de la empresa, ni el nivel jerárquico del funcionario competente para recibir el reclamo, por lo que queda a discreción de la institución, en atención a su orgánica interna, determinar quién lo será9. A su vez, se reconoce la posibilidad del trabajador de recurrir directamente ante la Inspección del Trabajo. En este sentido, útil resulta el modelo de reglamento que otorga la Asociación Chilena de Seguridad, en el cual se sugiere a la empresa derivar las denuncias a la Inspección del Trabajo, dentro de los plazos legales, para que realice la investigación respectiva.

Esta mención en el reglamento reviste especial importancia al considerar datos históricos, tales como la encuentra del Centro de Estudios de la Mujer de 1993, en la que se nos indicaba que el 42,3\% de las asediadas manifestó que al sufrir acoso sexual recurrirían a la jefatura máxima, al jefe directo o a alguna institución pública, en cir-

9. Para revisar las eventuales vulneraciones que podría sufrir el trabajador denunciado, véase Ramos Muñoz y Sánchez Romero (2015). 
cunstancias que el $21,3 \%$ señala que no recurriría a persona alguna y el $32 \%$ que no sabe dónde acudir (Délano y Todaro, 1993).

De las medidas de resguardo. Tras recibida la denuncia por el empleador, según el artículo 211-B inciso 1 del Código del Trabajo, se deberán adoptar las medidas de resguardo necesarias respecto de los involucrados, en consideración de la gravedad de los hechos imputados y las posibilidades derivadas de las condiciones de trabajo. Tales medidas de resguardo podrán ser adoptadas unilateralmente por el empleador, en virtud de su ius variandi (artículo 12 del Código del Trabajo), debiendo, sin embargo, respetarse los límites de tal institución y siempre adoptarse en atención a la gravedad de los hechos imputados (Ordinario 5268/309 de la Dirección del Trabajo).

Por el contrario, si la denuncia fue realizada directamente a la Inspección del Trabajo, ésta sugerirá, a la brevedad posible, la adopción de determinadas medidas de resguardo al empleador.

De la investigación de la denuncia. En caso de ser llevada por la Inspección del Trabajo, esta investigación se encuentra regulada por la Circular 88 de la Dirección del Trabajo, dictada el 5 de julio de 2001. Allí se establece que, recibida la denuncia, se le asignará un fiscalizador, de preferencia aquellos con experiencia en el tema o que tengan habilidades para la mediación y tratamiento de conflictos. Posteriormente, se hará una visita inspectiva, la que debe contemplar en su logística que, si se alcanzan suficientes antecedentes como para suponer o presumir la existencia del acoso, se ponga un especial acento en encarar al presunto acosador para, tras comprobar o presumir razonablemente la efectividad de la denuncia, inhibir su repetición. De igual forma, se buscará involucrar a los superiores jerárquicos de la empresa para hacerles ver su responsabilidad.

Señalado lo anterior, pasa la referida circular, de manera muy preocupante, a indicar:

El enfoque y la orientación para tratar el tema están más relacionados con la prevención que con la actitud punitiva o sancionadora, pues, además de las dificultades de acreditación de las conductas, no existe una sanción específica para ellas en la legislación laboral. Así, se espera que la aproximación a la materia en comento tenga un carácter educativo, más bien de gestión oficiosa y mediadora tanto para empleadores como para trabajadores. Se procurará, conjuntamente con poner fin a las posibles conductas acosadoras, preservar la relación laboral evitando eventuales represalias [sic] (Circular 88 de la Dirección del Trabajo).

Pese a lo evidentemente retrasado de tal párrafo, puesto que la legislación en esta materia fue modernizada en 2005, con la tipificación del acoso sexual, esta circular sigue siendo la que ordena el actuar de los inspectores del trabajo a la hora de fiscalizar una denuncia por acoso sexual, por lo que no deja de ser preocupante. 
Por su parte, en caso de que la denuncia se interponga ante el empleador, se otorga una opción al mismo para seguir la investigación de manera interna o, en un plazo de cinco días, remitir los antecedentes a la Inspección del Trabajo respectiva, con un plazo fatal para el término de la investigación de treinta días. Además, se señala que toda la investigación interna debe llevarse por escrito, en estricta reserva, lo que garantiza a ambas partes ser oídas y fundamentar sus dichos. Por último, las conclusiones que se alcancen tras la misma deben de remitirse a la Inspección del Trabajo respectiva.

Si bien nada se indica del plazo para que el empleador remita las conclusiones de su investigación a la Inspección, la Dirección del Trabajo ha indicado que tal es de cinco días (Ordinario 100/o02 de la Dirección del Trabajo). Debe de notarse, además, que no se hace referencia al funcionario que deberá investigar la denuncia, ni siquiera indicando si deberá tener un grado de superioridad jerárquico al denunciante o denunciado, lo que deja absoluta libertad al empleador en este sentido.

Tras este procedimiento, las conclusiones de la investigación realizada por la Inspección del Trabajo, o las observaciones que otorgue de las conclusiones de la investigación interna, serán puestas en conocimiento del empleador, denunciante y denunciado. Si bien no se señala qué tipo de observaciones puede hacer el órgano administrativo, se ha entendido que serán de carácter eminentemente jurídico, refiriéndose al cumplimiento de los principios de bilateralidad, escrituración y secreto, y a la calificación jurídica de los hechos constitutivos de acoso sexual (Lizama Portal y Ugarte Cataldo, 2005: 43).

De las medias a tomar como resultado de la investigación. Finalmente, se señala que, en mérito de tal informe de la Inspección del Trabajo, en un plazo de quince días contados desde su recepción, el empleador deberá disponer y aplicar las medidas y sanciones que corresponda en contra del trabajador culpable de acosar sexualmente a otro ${ }^{10}$. La doctrina ha señalado que tales sanciones tienen como finalidad la intimidación en contra del sancionado y restantes trabajadores, en búsqueda de un desenvolvimiento normal de la actividad empresarial y convivencia entre los trabajadores en el futuro (Fernández Toledo, 2015a) ${ }^{11}$.

Las mismas consisten en la simple amonestación verbal, la amonestación escrita, multa de hasta $25 \%$ de la remuneración diaria y el despido por conductas indebidas de carácter grave, acorde al artículo 160 número 1 del Código del Trabajo.

En definitiva, las sanciones que se establezcan deberían haber sido tomadas, a lo menos, 55 días después de recibida la denuncia de acoso sexual.

10. Sobre la finalidad de esta sanción, resulta interesante la publicación de Fernández Toledo (2015a). 11. Se otorga un muy interesante análisis del poder disciplinario del empleador en Fernández Toledo (2015b). 


\section{Respecto del reclamo por infracción del principio de igualdad de remuneraciones}

Señala el Código del Trabajo, en su artículo 62 bis, que:

El empleador deberá dar cumplimiento al principio de igualdad de remuneraciones entre hombres y mujeres que presten un mismo trabajo, no siendo consideradas arbitrarias las diferencias objetivas en las remuneraciones que se funden, entre otras razones, en las capacidades, calificaciones, idoneidad, responsabilidad o productividad (Decreto Fuerza del Ley 1, artículo 62 bis).

De esta forma, se elimina la posibilidad de hacer diferencias en la remuneración de los trabajadores del mismo cargo en atención al sexo de la persona, sin perjuicio de que las causales que se señalan para establecerse diferencias resultan bastante interpretables, sin permitirse un efectivo control por este punto.

Es así como, pese a la existencia de esta normativa desde 2009, según datos de INE, en octubre de 2012, tres años después de haberse agregado este precepto a nuestro ordenamiento laboral, la brecha salarial de ocupados era en Chile de $32,3 \%$, vale decir, en promedio las mujeres trabajadoras en nuestro país ganaban \$161.996 menos que los hombres trabajadores. El rubro con mayor desigualdad era el de oficiales, operarios y artesanos de artes mecánicas, con una brecha de 65,9\% (\$223.493) y el de menor el de los empleados de oficina, con una brecha de $19 \%$ (\$77.974).

Este mecanismo represivo jurídico, según el artículo 154 número 13 del Código del Trabajo, indica que tal reclamo y la respuesta del empleador deberán constar por escrito y estar debidamente fundamentados. A su vez, la respuesta del empleador ha de otorgarse en un plazo no mayor a treinta días desde efectuado el reclamo por parte del trabajador.

Por su parte, el artículo 62 bis indica que las diferencias salariales entre trabajadores hombres y mujeres no pueden ser arbitrarias, entendiendo que no lo son aquellas objetivamente fundadas en las razones que allí se indican. Señala en su inciso segundo, que, tras sustanciarse con acuerdo a lo dispuesto en el reglamento, este reclamo se sustanciará con acuerdo a las normas del procedimiento de tutela laboral, lo que de igual forma podría haber sido inferido toda vez que tal procedimiento se aplicará a los actos discriminatorios, dentro de los cuales, sin lugar a duda, se encuentra realizar diferencias salariales arbitrarias en atención al sexo de la persona.

Así, se reconoce constantemente en la jurisprudencia nacional que

al comparar remuneraciones no basta establecer diferencias meramente numéricas, pues para que ellas tengan valor irrefutable y objetivo deben homologarse también las completas circunstancias que a cada trabajador y a cada trabajadora correspondan. De modo que, si se acreditan circunstancias diferentes, resultará lógico colegir que las consecuencias, en este caso el monto de los salarios, serán también 
diferentes. La actuación administrativa, antecedente de este procedimiento de tutela, debía considerar todos los factores que pudieran provocar legítimas diferencias ${ }^{12}$.

Por su parte, como un paso para buscar dotar de objetividad a los criterios por los cuales se fija una remuneración, el mismo artículo 154 del Código del Trabajo indica en su numeral sexto que en instituciones con doscientos trabajadores o más, el reglamento deberá incluir un registro que consigne los diversos cargos o funciones en la empresa y sus características técnicas esenciales. Esta obligación resulta de suma utilidad a la hora de analizar una diferenciación arbitraria basada en el sexo en las remuneraciones de los trabajadores, toda vez que permite saber qué hace, esencialmente, cada cargo, pues se podría descubrir cargos que, teniendo diverso título, realizan la misma función, lo que facilita el reclamo por quien resulte afectado.

Sin embargo, sigue resultando corto este avance por los múltiples límites que reconoce, primero en cuanto a que sólo sea un deber para grandes empresas, en los términos del artículo 505 bis del Código del Trabajo. Además, se limita en demasía esta institución en tanto se otorgan demasiadas posibles justificaciones que, con una aparente objetividad, pueden albergar una discriminación, tal como es la capacidad e idoneidad del trabajador, por nombrar sólo algunos.

\section{Despido por causa grave}

Otra medida que otorga la legislación es la de que el empleador ponga término al contrato de trabajo, sin derecho a indemnización alguna, de aquel trabajador que incurra en alguna de las causales que señala expresamente el artículo 160 del Código del Trabajo.

En este sentido, se señala:

1. Alguna de las conductas indebidas de carácter grave, debidamente comprobadas, que a continuación se señalan:

b) Conductas de acoso sexual.

f) Conductas de acoso laboral (Decreto con Fuerza del Ley 1, artículo 160).

Podemos conceptualizar la terminación del contrato de trabajo como el fenómeno jurídico por el cual se extingue el contrato, queda disuelta la relación laboral y dejan de existir para las partes las obligaciones jurídicas y ético-jurídicas, patrimoniales y personales que las vinculaban (Thayer y Novoa Fuenzalida, 2009: 28).

Debe de destacarse que cualquiera de estas causales ha de ser de gravedad y debidamente comprobada, entendido como que se acredite en el proceso en forma indubitable, de manera que produzca sobre el sentenciador plena convicción sobre su configuración (Thayer y Novoa Fuenzalida, 2009: 50).

12. Sentencia de Corte de Apelaciones de Valparaíso, rol 297-2015, 29 de septiembre de 2015, recurso de nulidad, considerando quinto. 
En este sentido, siempre habrá un riesgo para el empleador al invocar alguna de estas causales, pues debe contar con antecedentes probatorios suficientes como para darles aplicación. Así las cosas, ha de realizarse dos precisiones.

\section{Respecto del acoso sexual ${ }^{13}$}

El hecho de incurrir el trabajador en esta conducta, encontrándose ello acreditado tras la realización de la investigación que el empleador o la Inspección del Trabajo llevan, siempre ha de ser sancionado mediante la aplicación de la medida de despido por causa grave. Ello, en tanto es la ley la que expresamente señala que será aplicada en caso de conductas de acoso sexual. A su vez, la propia ley resguarda al empleador que, erróneamente, tras realizar un procedimiento investigativo acorde a las normas ya señaladas, despide a un trabajador por aplicación de esta causal.

En este sentido, el artículo 168 del Código del Trabajo señala que aquel trabajador cuyo contrato terminare por aplicación de los artículos 159, 160 y 161, que considere su aplicación injustificada, indebida o improcedente, o que no se ha invocado alguna causal legal, podrá recurrir al juzgado competente para que éste ordene el pago de la indemnización sustitutiva del aviso previo y por años de servicio, aumentada, en lo que nos interesa, en $80 \%$ si se hubiera dado término por aplicación indebida de las causales del artículo 160 del Código del Trabajo, entre las cuales se cuenta la conducta de acoso sexual. Además, si se hubiere aplicado esta causal, y el despido fuere carente de motivo plausible, la indemnización se incrementará en $100 \%$. Todo lo cual será determinado por el juez de la causa.

Sin embargo, no se aplicará tal recargo si se considerare el despido injusto, indebido o improcedente, según mencionan los artículos 154 número 12 y 168 el Código del Trabajo, cuando el empleador haya realizado la investigación por denuncia de acoso sexual siguiendo los lineamientos que la legislación establece, esto es, cumpliendo los plazos indicados y guardando los principios formativos del procedimiento que allí se establecen.

\section{Respecto del acoso laboral}

Señala el ya citado artículo 2 del Código del Trabajo ${ }^{14}$ :

Asimismo, es contrario a la dignidad de la persona el acoso laboral, entendiéndose por tal toda conducta que constituya agresión u hostigamiento reiterados, ejercida por el empleador o por uno o más trabajadores, en contra de otro u otros trabaja-

13. Ordinario $1133 / 36$ de 2005 .

14. Elementos muy similares consideran Caamaño Rojo (2001) Caamaño Rojo y Ugarte Cataldo (2014) y Ugarte Cataldo (2012). 
dores, por cualquier medio, y que tenga como resultado para el o los afectados su menoscabo, maltrato o humillación, o bien que amenace o perjudique su situación laboral o sus oportunidades en el empleo (Decreto con Fuerza de Ley 1, artículo 2).

La mentada legislación surgió para ratificar una línea que se daba en la práctica, tanto por el actuar de la Dirección del Trabajo como por el de los Tribunales de Justicia, quienes desde el establecimiento del Procedimiento de Tutela de Derechos Fundamentales habían comenzado a recoger, jurisprudencialmente, esta institución. La relevancia de establecer esta institución se hacía manifiesta especialmente en los datos manejados por la entidad administrativa, por aplicación de la encuesta CERC sobre la percepción de la ciudadanía del mundo del trabajo, en cuyas consultas a nivel nacional destacaba que, en 2002, ante la pregunta de si, en general, los trabajadores recibían un trato respetuoso por parte de sus jefes en el trabajo, el $69 \%$ indicó que no y sólo el $26 \%$ que sí. En 2005, ante la pregunta: «¿Cree usted que en Chile los empleadores otorgan un trato digno a los trabajadores?», sólo el $22 \%$ opinó que sí, el $49 \%$ señaló que a veces y el $24 \%$ que nunca o casi nunca. En abril del año en curso, el $39 \%$ de los trabajadores encuestados señaló que en su empresa han ocurrido malos tratos de parte de jefes a trabajadores, mientras que el $23 \%$ indicó que ocurrió alguna situación de acoso laboral (Acción Empresas, 2017).

De esta forma, el hecho de que un trabajador incurra en esta conducta, de igual forma hace que el empleador pueda poner término a su contrato de trabajo. Sin perjuicio de ello, debe entenderse sujeto a las mismas limitaciones ya señaladas, en cuanto a la gravedad y comprobación de la misma, lo que lleva a una aplicación muy limitada.

\section{Despido indirecto o autodespido (artículo 171 del Código del Trabajo) ${ }^{15}$}

Recoge la normativa la posibilidad de que sea el empleador el que incurra en alguna de las conductas señaladas expresamente en el artículo 171 del Código del Trabajo, de aquellas contenidas en el artículo 160. Indica, en particular, que procederá cuando concurran conductas indebidas de carácter grave (número 1), entre los que se cuenta la falta de probidad, acoso sexual, vías de hecho, injurias, conducta inmoral que afecte a la empresa y acoso laboral. De igual forma (número 5), los actos, omisiones o imprudencias temerarias que afecten a la seguridad o al funcionamiento del establecimiento, la seguridad o la actividad de los trabajadores o su salud. Por último, si incumpliera gravemente las obligaciones que impone el contrato de trabajo (número

15. Es por esta vía que la Corte Suprema dictó un fallo emblemático en la materia, al señalar que la negligencia imputable al empleador consistía en no haber adoptado las medidas adecuadas para resguardar la salud e integridad tras conocer prácticas que una trabajadora calificaba como acoso sexual. Su análisis en Carvajal Godoy (2005: 43-48). 
7). De igual forma, se señala que responderá acorde a estos preceptos aquel empleador que, mientras investiga y sanciona una denuncia de acoso sexual, no respete lo dispuesto en los artículos 211-A y siguientes.

En este sentido, si fuere el empleador el que incurre en las conductas indicadas, el trabajador podrá poner término al contrato y recurrir al juzgado respectivo, en un plazo de sesenta días hábiles desde la terminación del mismo, para que éste ordene se otorguen la indemnización sustitutiva del aviso previo, señalada en el artículo 162 del Código del Trabajo, y la indemnización por años de servicio, contenida en los incisos 1 y 2 del artículo 163 . Todas ellas aumentadas en $50 \%$ en el caso de la causal de incumplimiento grave de las obligaciones del contrato, o hasta en $80 \%$ en el caso de aquélla de los números 1 o 5 del artículo 160 .

Precisa posteriormente el artículo 171 que cuando se invoque la falta de probidad del empleador, el acoso sexual o el acoso laboral, se podrá reclamar a la vez las indemnizaciones a las que el trabajador tenga derecho. Para finalizar, indica que si el Tribunal rechaza el reclamo del trabajador se entenderá que el contrato ha terminado por renuncia del mismo. Lo que podría tenerse como una sanción para aquél que invoca esta causal sin fundamento suficiente.

Más, el nuevo inciso final agregado en la Ley 20.607 de agosto de 2012 es una sanción aún más directa y evidente, en tanto se señala que aquel que invoque la causa de acoso sexual o acoso laboral para dar término a su contrato falsamente o con el propósito de lesionar la honra del empleador, siempre que la demanda sea declarada carente de motivo plausible por el juez del Trabajo, estará obligado a indemnizar los perjuicios causados al afectado. Además, si sumado a todo lo anterior se invocan estas causales maliciosamente, estará sujeto también a otras acciones legales que procedan.

\section{Procedimiento de tutela laboral (485 y siguientes) ${ }^{16}$}

Este medio de protección otorgado por la legislación laboral, que podría ser el más directo de todos, es el procedimiento de tutela laboral, contenido en el párrafo 6 del título 1 del libro 5 del Código del Trabajo. Tiene lugar ante una vulneración genérica de derechos fundamentales, consagrados en el propio artículo 485 del Código del Trabajo, o en particular por el inciso segundo del mismo precepto.

Este procedimiento tuvo una aplicación histórica fuerte en la lucha contra el acoso laboral, en tanto mientras esta institución no fue recogida en la legislación chilena, la herramienta jurídica se utilizó ampliamente para resguardar al trabajador ante cualquier vulneración de sus derechos fundamentales en el ámbito laboral, por lo que corresponde a los jueces laborales la tarea de velar por su protección y eficacia (Caamaño Rojas y Ugarte Cataldo, 2014: 77-80).

16. Véase Caamaño Rojo y Ugarte Cataldo (2014: 67-90). 
Además, cabe destacar que tal utilidad histórica no ha sido modificada por la regulación de esta temática en el ordenamiento laboral chileno, en tanto la Ley 20.607 de agosto de 2012 omite modificar o incluso tratar de modo alguno el artículo 485. Esto ha sido comprendido por la doctrina como que el legislador ha deseado mantener la competencia de los tribunales laborales, en iguales términos, respecto del acoso laboral (Caamaño Rojas y Ugarte Cataldo, 2014: 87).

Por último, no puede dudarse de lo beneficioso de la aplicación de este procedimiento ante estas vulneraciones, en especial en atención a lo señalado en el artículo 493, conocido por prueba indiciaria, indirecta o circunstancial. En tanto, lo que corresponde probar al trabajador son los «hechos que generen en el juez una sospecha razonable de que ha existido una conducta lesiva» (Ugarte Cataldo, 2009b). De esta forma, cuando los antecedentes aportados por la parte denunciante resulten indicios suficientes de que se ha producido la vulneración de derechos fundamentales, será el denunciado quien deba explicar los fundamentos de las medidas adoptadas y su proporcionalidad.

De esta forma, resulta de absoluta utilidad para resguardar los derechos de los trabajadores ante situaciones de acoso sexual, acoso laboral e, incluso, ante la vulneración del principio de igualdad de remuneraciones.

Sin embargo, y pese a lo amplio que podría parecer el tratamiento del acoso laboral y su resguardo por la tutela de derechos fundamentales, el legislador se ha encargado de poner ciertos límites que presenten cargas probatorias para el denunciante, todo con miras a la seguridad jurídica (Caamaño Rojas y Ugarte Cataldo, 2014: 82-87). En este sentido, será el trabajador el encargo de probar que la conducta antijurídica proviene de su empleador, de sus compañeros de trabajo o, por último, que ambos han concurrido, de acción u omisión, en la situación vulneratoria.

Otro límite al respecto es la exigencia de reiteración de la conducta, lo que genera un efecto negativo (Caamaño Rojas y Ugarte Cataldo, 2014: 85), toda vez que, al no configurarse la persistencia temporal de la agresión, la lesión de derechos fundamentales sufrida por el trabajador, aquello verdaderamente importante, pasa a ser minimizado.

\section{Recurrir a la Inspección del Trabajo}

Como es habitualmente conocido por los trabajadores, siempre es posible acudir a la Inspección del Trabajo para denunciar alguna vulneración de derechos. Así lo establece el artículo 505 del Código del Trabajo, el cual señala que la fiscalización del cumplimiento de la legislación laboral y su interpretación corresponde a la Dirección del Trabajo, la que actuará en la forma en que su Ley Orgánica Constitucional y demás leyes reguladoras determinan. 


\section{Reflexiones finales}

Una primera conclusión es que los mecanismos otorgados por el legislador tienen un carácter represivo, sin contar con alguno que busque evitar o prevenir el actuar lesivo. Tal mecanismo podría ser, por ejemplo, que al momento de ingresar un trabajador a la empresa, se le otorgue una charla sobre acoso sexual o laboral.

Segundo, en cuanto a la reiteración de la violencia sufrida por la persona agredida, en todos los mecanismos señalados debe constar la identidad de la víctima. Por ejemplo, pese a que el procedimiento de investigación de acoso sexual debe ser secreto, a la hora de cursarse una multa administrativa por ello, siempre se menciona su nombre, lo que podría llevar a que personas ajenas a la investigación se enteren de la misma sólo por ser los encargados de recibir las multas dentro de la empresa.

Respecto del procedimiento de investigación de acoso sexual por el empleador, no se cuenta con suficientes resguardos para la víctima, toda vez que, normativamente, no se establece que el funcionario investigador requiera formación ni rango específico. Tampoco se establecen, normativamente, resguardos para el agresor. Todo queda, por tanto, sólo a criterio del empleador.

Sobre el despido por causal grave, su aplicación puede resultar limitada debido a los resguardos que se deben al trabajador. Esto porque utilizarlo redunda en un riesgo demasiado alto para el empleador, quien de seguro, especialmente ante acoso laboral, preferirá buscar una medida alternativa, que podría ser menos grave para el agresor, en perjuicio del denunciante.

Con relación al autodespido, resulta insuficiente, en tanto lleva a que la persona que ha sufrido una situación como las descritas, además, pierda su fuente de ingresos y ocupación habitual. Esto sin lugar a duda llevaría a ampliar los efectos psicológicos negativos sufridos por la víctima.

Por su parte, el procedimiento de tutela laboral parece el más adecuado; sin embargo, también se pone en la situación del término de la relación laboral respecto del vulnerado, por lo que de igual forma envuelve un perjuicio psicológico para él. A su vez, las cargas probatorias que se imponen al recurrir por acoso laboral o por vulneración al principio de igualdad de remuneraciones hacen que no resguarde debidamente los derechos de los afectados, al constatar la vulneración, pero no sancionarla por falta de requisitos.

Como se dijo, sobre la igualdad remuneratoria, ella resulta insuficiente por las justificaciones legales que se otorgan, en tanto son de tal magnitud que permiten fundar cualquier tipo de diferencia, incluso si ella resulta discriminatoria, pues se le recubre de legalidad mediante cualquiera de los conceptos claves que allí se señalan.

Por último, como se reconoce desde la propia institución, las multas administrativas no tienen un lugar especial en cuanto a crear un buen ambiente de trabajo, sino que ellas se imponen sólo como sanción, sin poder modificar los elementos vulneratorios. 
Por tanto, en el entendido de que las relaciones de subordinación y dependencia han avanzado hacia un punto en el cual las personas pasan gran parte de su vida en el contexto de una empresa, pues se mantienen largas horas al día prestando servicios a su empleador, un ordenamiento jurídico que propenda a buscar crear y mantener relaciones laborales sanas y carentes de vulneración debe ser la meta máxima del sistema.

En este sentido, falla el ordenamiento jurídico laboral, puesto que pone su mirada sólo en la sanción ante el hecho dañino en el que se incurre, sin contemplar mecanismos que permitan adecuar las condiciones de trabajo a aquellas que eviten la ocurrencia de estos hechos.

\section{Referencias}

ACCión Empresas (2017). Relaciones laborales para un desarrollo sostenible. Disponible en http://bit.ly/2vMY6aY.

Agencia Europea de Derechos Fundamentales (2014). Violence against women: an EU-wide survey. Main results. Viena. Disponible en http://bit.ly/1BSvRbD.

Baile Ayensa, José Ignacio (2008). Estudiando la homosexualidad. Teoría e investigación. Madrid: Pirámide.

CAAmaño Rojo, Eduardo (2001). «La noción de acoso moral laboral o 'mobbing' y su reconocimiento en la jurisprudencia en Chile». Revista de Derecho de la Pontificia Universidad Católica de Valparaíso, 37: 215-240. DOI: 10.4067/ So718-68512011000200005.

CaAmaño Rojo, Eduardo y José Luis Ugarte Cataldo (2014). «El acoso laboral: Tutela y prueba de la lesión de los derechos fundamentales». Ius et Praxis, 20 (1): 67-90. DOI: 10.4067/So718-00122014000100004.

Carrasco Oñate, Celina y Patricia Vega López (2009). Acoso sexual en el trabajo. ¿Denunciar o sufrir en silencio? Análisis de denuncias.. Santiago: Dirección del Trabajo.

Carvajal Godoy, Gabriela (2005). «Antecedentes de la legislación sobre acoso sexual: Jurisprudencia y tramitación legislativa». En Eduardo Caamaño Rojo y otros (editores), El acoso sexual en la empresa. Análisis de la Ley 20.005 (pp. 43-48). Santiago: Lexis-Nexis.

Comisión Europea (1998). Sexual harassment at the workplace in the European Union. Bruselas. Disponible en http://bit.ly/2w3zAls.

Corcoy Bidasolo, Mirentxu (2010). «Problemática jurídico-penal y político-criminal de la regulación de violencia de género y doméstica». Revista de Derecho de la Pontificia Universidad Católica de Valparaíso, 34: 305-347. DOI: 10.4067/ So718-68512010000100009. 
Délano, Bárbara y Rosalba Todaro (1993). Asedio sexual en el trabajo. Santiago: Centro de Estudios de la Mujer.

Fernández Toledo, Raúl (2015a). «El poder disciplinario del empleador: Configuración jurídica de la sanción laboral que puede imponer al trabajador dependiente». Revista de Derecho de la Pontificia Universidad Católica de Valparaíso, 44: 267-316. DOI: 10.4067/So718-68512015000100013.

-. (2015b). «Poder disciplinario del empleador: Configuración jurídica de la falta laboral cometida por el trabajador dependiente». Ius et Praxis, 21 (2): 423-46o. DOI: 10.4067/So718-00122015000200008.

Gamonal Contreras, Sergio (2004). Ciudadanía en la empresa o los derechos fundamentales inespecíficos. Montevideo: Fundación de Cultura Universitaria.

-. (2008). El procedimiento de tutela de derechos laborales. $2 .^{\mathrm{a}}$ ed. Santiago: Legal Publishing.

-. (2015). La eficacia diagonal u oblicua y los estándares de conducta en el derecho del trabajo. Santiago: Thomson Reuters.

Gauché Marchetti, Ximena (2011). Sexualidad diversa y discriminación. Una mirada desde el derecho internacional de los derechos humanos. Madrid: Editorial Academia Española.

Instituto Nacional de Estadísticas (2016). «Encuesta nacional de empleo». Disponible en http://bit.ly/2vNtSF8.

Jewkes, Rachel (2002). «Intimate partner violence: Causes and preventions». The Lancet, 359 (9.315): 1.423-1.429. DOI: 10.1016/So140-6736(02)08357-5.

Lizama Portal, Luis y José Luis Ugarte Cataldo (2005). Nueva ley de acoso sexual. Santiago: Lexis-Nexis.

Organización Internacional del Trabajo (2003). ABC de los derechos de las trabajadoras y la igualdad de género. $1^{\mathrm{a}}$ ed. Ginebra: OIT.

Oficina Regional para las Américas de la Organización Mundial de SaLUD (2002). Informe mundial sobre la violencia y la salud: Resumen. Disponible en http://bit.ly/WrmOvv.

Ramos Muñoz, Ana Paula y Danilo Sánchez Romero (2015). La idoneidad del procedimiento de investigación interna por parte del empleador ante la denuncia de acoso sexual. Tesis de pregrado. Santiago: Departamento de Derecho del Trabajo y Seguridad Social, Facultad de Derecho, Universidad de Chile.

Shibley Hide, Janet y John DeLamater (2006). Sexualidad humana. Ciudad de México: Mc Graw-Hill Interamericana.

Servicio Médico Legal (2016). Norma general técnica para la atención de víctimas de violencia sexual. Santiago: Servicio Médico Legal. Disponible en http://bit. ly/2vJWgrC.

Thayer, William y Patricio Novoa Fuenzalida (2009). Manual de derecho del trabajo. Tomo 4. Santiago: Editorial Jurídica de Chile. 
Ugarte Cataldo, José Luis (2012). «El acoso laboral: Entre el derecho y la psicología». Revista de Derecho de la Pontificia Universidad Católica de Valparaíso, 39: 221-231. DOI: 10.4067/So718-68512012000200008.

-. (2009a) Tutela de derechos fundamentales del trabajador. Santiago: Abeledo Perrot Legal Publishing.

-. (2009b) «Tutela laboral de derechos fundamentales y carga de la prueba». Revista de Derecho de la Pontificia Universidad Católica de Valparaíso, 33: 215-228.

\section{Sobre el autor}

Sergio Esteban Mundaca Castillo es abogado. Licenciado en Ciencias Jurídicas y Sociales de la Universidad de Chile. Su correo electrónico es sergiomundacc@ ug.uchile.cl. 
